\title{
Capsaicin: Plants of the Genus Capsicum and Positive Effect of Oriental Spice on Skin Health
}

\author{
Shahnai Basharat ${ }^{a}$ Syed Amir Gilani ${ }^{b}$ Faiza Iftikhar ${ }^{a} \quad$ Mian Anjum Murtazac \\ Ayesha Basharat $^{d}$ Ahsan Sattar $^{\mathrm{e}}$ Muhammad Mustafa Qamar ${ }^{\mathrm{f}}$ \\ Muhammad Alig \\ a University Institute of Diet \& Nutritional Sciences, The University of Lahore, Sargodha, Pakistan; ${ }^{\text {bDean, Faculty }}$ \\ of Allied Health Sciences, The University of Lahore, Lahore, Pakistan; 'Department of Food Sciences, University \\ of Sargodha, Sargodha, Pakistan; 'Sargodha Medical College, University of Sargodha, Sargodha, Pakistan; ${ }^{e}$ Food \\ Microbiology and Technology, Bahaudin Zikriya University, Multan, Pakistan; 'Department of Physical Therapy, \\ Sargodha Medical College, The University of Sargodha, Sargodha, Pakistan; IInstitute of Allied Health Sciences, \\ Sargodha Medical College, The University of Sargodha, Sargodha, Pakistan
}

\section{Keywords}

Transient receptor potential cation channel, subfamily V, member 1 - Capsicum · Capsaicin · Psoriasis · Skin · Atopic dermatitis

\section{Abstract \\ Background: Capsaicin, the main pungent ingredient in hot chili peppers, causes excitation of small sensory neurons. It also provides the basic pungent flavor in Capsicum fruits. Summary: Capsaicin plays a vital role as an agonist for the TRPV1 (transient receptor potential cation channel, subfam- ily $\mathrm{V}$, member 1) receptor. TRPV1 is essential for the reduc- tion of oxidative stress, pain sensations, and inflammation. Therefore, it has many pros related to health issue. Activa- tion and positive impact of TRPV1 via capsaicin has been studied in various dermatological conditions and in other skin-related issues. Past studies documented that capsaicin plays a vital role in the prevention of atopic dermatitis as well as psoriasis. Moreover, TRPV1 is also very important for skin health because it acts as a capsaicin receptor. It is found in}

nociceptive nerve fibers and nonneural structures. It prompts the release of a compound that is involved in communicating pain between the spinal cord nerves and other parts of the body. Key Messages: Here, we summarize the growing evidence for the beneficial role of capsaicin and TRPV1 and how they help in the relief of skin diseases such as inflammation, permeation, dysfunction, atopic dermatitis, and psoriasis and in pain amplification syndrome.

(c) 2021 S. Karger AG, Basel

\section{Introduction}

Background

Capsaicin, derived from the plants of the genus Capsicum [1], belongs to the Solanaceae family. It is the main pungent ingredient found in hot chili peppers. It is the most extensively consumed chili in all around the world. The domesticated species include Capsicum annuum, Capsicum frutescens, and Capsicum chinense[2]. The Capsicum genus is the only peppers plant that produces karger@karger.com

www.karger.com/spp

Karger ${ }^{\prime}=$ (c) 2021 S. Karger AG, Base

97 Alfareid Garden Phase-1
Sargodha 40100 (Pakistan)

shahnaibhatti@gmail.com 
Fig. 1. Chemical structure of capsaicin and
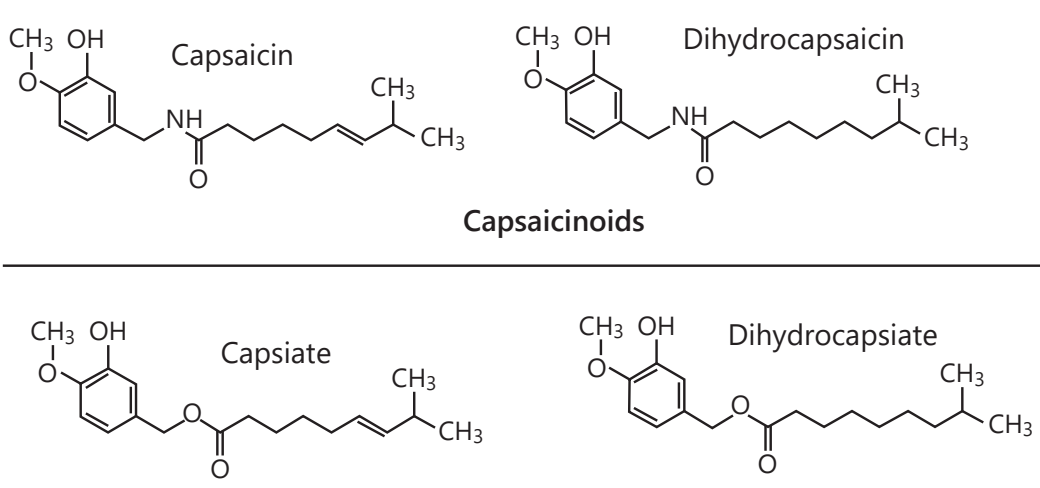

Capsaicinoids

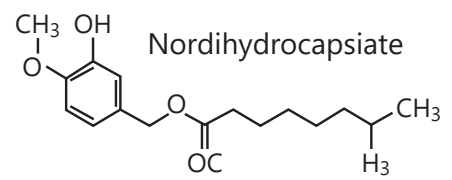
capsaicinoids.

alkaloids carotenoids and flavonoids and capsaicinoids together. The first 2 categories of metabolites tend to be responsible for the attractive colors of the peppers ranging from green to red [3]. The capsaicinoids, however, attribute a taste characteristic known as pungency [4]. Capsicum chinense is the most pungent of them all [5]. Capsaicinoids are believed to have strong pharmacological properties that could be used in pain relief, weight reduction, cardiovascular conditions, and cancer prevention besides providing relief in gastrointestinal diseases. Capsaicin and other 14 homologs are identified as major active components of chili pepper [6]. Capsaicin and dihydro capsaicin are synthesized as main molecules.

\section{Chemical Structure}

Capsaicin was first purified in 1876 [7], but its structure was started to be explained in 1919 [8]. Now, the properties and structure of capsaicin are clarified (Fig. 1). Capsaicin has a nonpolar phenolic structure, and therefore it cannot be solubilized in water. Nonpolar solvents such as ether, benzene, dimethyl sulfoxide, and acetone are used to extract and maintain capsaicin properties. Ethanol can be also used as a solvent due to its mixed properties. According to its chemical structure, capsaicin can be well absorbed when administrated topically or orally, reaching up to $94 \%$ of absorption [9].

\section{General Health Benefits of Capsaicin}

The use of pepper is documented in several civilizations. They started cultivating it, and then brought it in their consumption due to its outstanding properties [1013]. It got increasingly popular and well documented in $1600 \mathrm{BC}$. The fruit was used excitingly as pigments, food spices, and medicine $[14,15]$. At that time, it was used for stomach disorders and headaches [16]. Later, thereby, peppers are used in the industry as either dried powder (paprika) or oleoresin (extract of essential oil, waxes, carotenoids, flavonoids, and capsaicinoids). At the same time, it was also added to be an important application in food of military personnel [17].

Recent intensifying evidence suggests that capsaicin is advantageous in multifactorial metabolic disorders, cardiovascular diseases, obesity management, diabetes mellitus, cancers, dermatological conditions, and neurogenic bladder [18]. Capsaicin, besides this, also has a wide range of activities like analgesic, antipruritic, anti-inflammatory, antiapoptotic, antioxidant, and neuroprotective roles [19].Especially, its use as an anti-inflammatory compound in psoriasis, brachioradial pruritus, aquagenic pruritus, notalgia paresthetica, nodular prurigo, and pruritus produced in patients on hemodialysis is worth mentioning [20]. Capsaicin is now available as a prescribed drug in many markets of countries for clinical indications for the treatment, especially for pain [21]. 


\section{Capsaicin Synthesis}

Capsaicin is synthesized by 2 diverse in vivo pathways: (i) synthesis of phenylpropanoids leading to aromatic ring construction and (ii) the other being by metabolism of the fatty acid chain foremost to the hydrophobic acyl chain addition to form capsaicinoids [22]. Besides the main capsaicinoid presence, capsaicin, many other similar molecules with reduced pungency and resiniferoids are identified from the Capsicum species. All these compounds, related to capsaicin, share therapeutic properties in pain and other pathophysiology illnesses [23].

\section{Capsaicin Receptors}

\section{TRPV1 Receptor}

In the last few decades, numerous unprecedented studies on the vanilloid receptor yielded the identification of many members in the transient receptor potential (TRP) family. These receptors regulate $\mathrm{H}^{1+}, \mathrm{Na}^{1+}, \mathrm{Ca}^{2+}$, and $\mathrm{Mg}^{2+}$ intracellular concentrations [23]. The initial vanilloid receptor or VR1, later renamed as TRPV1, was identified in a subfamily [24]. The TRPV1 receptor is expressed in neurons and astrocytes, within the brain and spinal column, adipocytes, smooth muscle cells, vascular endothelial cells, hepatocytes, fibroblasts, various epithelia, T cells, and mast cells [25]. Capsaicin is shown to be attracted with high sensitivity and selectivity to the TRPV1 receptor. The receptor is sensitized with nanomolar concentrations $\left(\mathrm{EC}_{50}=99 \mathrm{NM}\right)$ which can be achieved after its ingestion orally which is followed by its high absorbility [26]. Capsaicin-related activation does not influence other TRP channels and the superfamily of the voltage-gated cation channel, including TRPV2TRPV6. Capsaicin interaction with the TRPV1 receptor acts in a "tail-up, tail down configuration." The tail interface is lured to the receptor through van der Waals forces. The head of the molecule interacts by hydrogen bonds between the vanillyl part and the amide neck at $E^{571}$ and $\mathrm{T}^{551}$ residues of the TRPV1 channel correspondingly. Furthermore, the slip into the vanilloid pocket, $\mathrm{Y}^{511}, \mathrm{G}^{570}$, and $\mathrm{I}^{569}$ residues, plays major steric facilitations to fit the capsaicin molecule in the groove (Fig. 2) [27].

All TRP receptors comprise either $\mathrm{K}^{+}$-selective channels with voltage-gated $\mathrm{Ca}^{2+}$ channels, voltage-regulated $\mathrm{Na}^{+}$channels, cyclic nucleotide gradient channels, or lastly 2-pore channels. It should be reminisced that the TRPV 1 receptor tends to be a nonselective cation channel that has more affinity toward $\mathrm{Ca}^{2+}$ than $\mathrm{Na}^{+}$ions $\left(\mathrm{P}_{\mathrm{Ca}} / \mathrm{P}_{\mathrm{Na}}\right)$. The

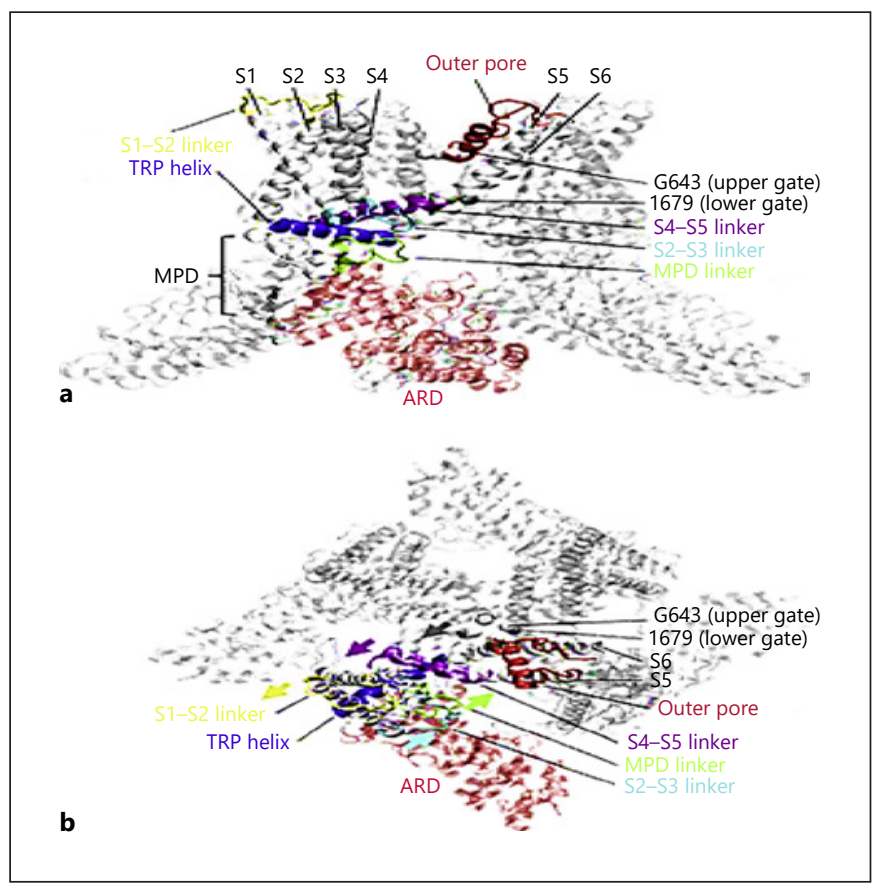

Fig. 2. a, b TRP helix structure. TRP, transient receptor potential.

TRPV receptors are divided into 3 groups with a gradient range of $0.1-20$ [28]. In context to the spatiotemporal regulation of $\mathrm{Ca}^{2+}$ within the cell, there is a silent mechanistic second intracellular, message signal which is most of the time present in the animal kingdom [29]. The capsaicin antagonistic activity toward the TRPV1 receptor leads to variable efflux/influx pore size. This regulates the divalent and monovalent cation relativities in a frame of seconds to minutes. Phosphorylation of $\mathrm{S}^{800}$ of the TRPV1 protein by protein kinase $\mathrm{C}$ ( $\mathrm{PKC}$ ) increases permeability and enhances inward currents [30]. With the influx of $\mathrm{Ca}^{2+}$, a cytosolic modulation occurs, by $\mathrm{Ca}^{2+}$-binding proteins such as calmodulin (CaM). CaM specifically interacts conformationally to the binding domains on TRP channels [31]. Recent work on CaM showed that it binds to the cardiac ryanodine receptor (RyR2) (CaM-RyR2). This is again imperative to the $\mathrm{Ca}^{2+}$ release and contraction [32]. Nuclear accretion of CaM is believed to be a contributing factor in pathological cardiac hypertrophy [32].

\section{TRPV1 Receptor Structure}

TRPV-1 receptor is a homotetramer. The cryoelectron microscope studies revealed that the TRPV1 architecture is made of 4 subunits that are symmetrically organized 
around the central conductive pore [33]. The heteromerization with other proteins is facing, however, an intense debate [34].

There are 28 such structures present in the TRPV1 structure [35]. The ankyrin repeats are the docking sites for the CaM protein. However, the carboxyl terminus, TRP helix, is assigned to a highly conserved helix that is used in its activation [36]. Specific capsaicin binding to TRPV1 is not yet elucidated nor illustrated in any form. Structural and architectural studies showed that the TRPV1 receptor is very similar to other voltage-gated $\mathrm{H}^{1+}, \mathrm{K}^{+}, \mathrm{Na}^{+}, \mathrm{Mg}^{2+}$, and $\mathrm{Ca}^{2+}$ channels [37]. The receptor exhibits a wide extracellular opening with a very short selective filter gate.

\section{Substance P}

The existence of TRPV1 in C-type peptidergic nociceptors is indicated by its colocalization with the main proinflammatory neuropeptides, calcitonin-gene-related peptide alpha ( $a$ CGRP) and substance $\mathrm{P}(\mathrm{SP})[38,39]$. SP and aCGRP play a vital role in the development and maintenance of neurogenic pain and inflammation as a genetic ablation of these peptides results in pain resistance [40-43]. All these neuropeptides are critically accumulated in large dense-core vesicles (LDCVs) and then released in response to proalgesic stimuli by a regulated, $\mathrm{Ca}^{2+}$-dependent, and SNARE-mediated secretory pathway [44].

LDCVs can also work as carriers of a plethora of signaling molecules such as ion channels as well as receptors that might enable fast modulation of neuronal excitability [45]. This finding documenting the explosive hypothesis related to proalgesic recruitment of TRPV1 channels is a mechanism occurring in peptidergic nociceptors. A well-known proalgesic agent, ATP, is used to investigate the mechanisms underlying TRPV1 sensitization among sensory neurons [45-47]. Tominaga et al. [41] revealed that ATP-induced TRPV1 potentiation in peptidergic nociceptors specifically involves the exocytotic mobilization of new channels to the cell surface. Particularly, knockout of aCGRP expression inhibited the ATPevoked TRPV1 delivery to the neuronal surface and prevented ATP-induced in vivo thermal hyperalgesia. Thus, algesic-induced exocytosis of TRPV1 channels in peptidergic nociceptors is a central mechanism in pain signaling [47].

\section{Capsaicin Mechanism in Action}

Several TRP channels are expressed in sensory endings of somatosensory neurons. These cells respond to both innocuous and noxious stimuli as discussed above. Their effect facilitates to open $\mathrm{Ca}^{2+}$-permeable TRPA1, TRPV1, and TRPM3 nonselective channels. The depolarization evokes the potential firing and propagation to CNS pain signals [48]. The mechanism leads to local cytosolic $\mathrm{Ca}^{2+}$ rise that triggers neuropeptide release and causes neurogenic inflammation. Recent extensive research did not address its biological implications. Capsaicin-sensitive receptors are now shown to influence various CNS cells [49].

Structurally and functionally, the TRPV1 receptor is divided into 3 compartments: (a) capsaicin-induced neurons (sensory) in the peripheral nervous system, (b) central nervous system neurons, and (c) tissues of nonneuronal origin. The TRPV1 receptor is triggered through many stimuli which includes heat, capsaicin, protons $(\mathrm{pH}<5.9)$, allicin and diallyl sulphides from garlic, gingerol from ginger, and piperine from black pepper. Toxic venoms of spider and jelly fish are also good agonists [50].

The first evidence of a selective action of capsaicin on C-polymodal nociceptors was obtained by the capsaicin-persuaded response of $\mathrm{C}$-fibers at the saphenous nerve [51]. Capsaicin-conjured mechanical allodynia appears very much dependent on protein kinases, especially PKA and PKC, and other G-coupled proteins. The presence of substrate $\mathrm{P}$ - produced by incentive of capsaicin - increases intracellular $\mathrm{Ca}^{2+}$ levels through inhibition of both high-voltage- and low-voltage-activated T-type calcium channels. This selective inhibition primes up both primary and secondary effects of calcium influx that responds to delayed sensitization of the TRPV1 receptor [52]. The activation process is believed to be positively regulated by calcineurin, a specialized calcium-dependent CaM enzyme. Calcineurin is phosphorylated at $\mathrm{T}^{370}$ by PKA. This modification causes capsaicin-induced analgesia [53]. Involvement of other phosphorylations regulates increased trafficking and extracellular expressions. The NMDA receptor, for instance, is modified at $S^{890}, S^{897}$, and $S^{896}$ that enhances its receptor activity. Similarly, modifications in the mitogen activated protein kinase (MAPK) pathway are linked to capsaicin activation where p38, an MAPK protein, is upregulated in the periphery and dorsal horns of the spinal cord [54]. 


\section{CGRP Peptide}

CGRP is a 37-amino acid peptide. The peptide exhibits 2 forms: $\alpha$-CGRP and $\beta$-CGRP isoforms. $\beta$-CGRP, investigated less, differs by 3 amino acids which are predominantly expressed at the enteric sensory system encoded by a separate chromosome 11 region [61]. The CGRP gene is mainly controlled by expression of the MAPK signaling pathway and TNFa, COX-2, NO, and iNOS-induced cytokines [55].

The CGRP product is countenance in both central and peripheral neurons. It is a potent vasodilatory peptide which relates to nociception transmission. The peptide is released from neurons and various neurogenic inflammatory cellular cytokines which provide a defense mechanism [56]. Both CGRP ( $\alpha$ and $\beta$ ) could be released by nonspecific stimuli in gastrointestinal tissues. Activation through capsaicin releases CGRP on the first stimuli. The second stimulus is effortless. This specific activation by high concentration of capsaicin releases only a-CGRP. $\beta$-CGRP is effective against neurons that are insensitive to TRPV1-capsaicin provocations [57].

From the recent literature, it is learned that activity associated with TRPV1 is the main transducer that links CGRP release. This activation causes local inflammation and sensitization of neuronal tissues related to pain. The human CGRP, specifically $\beta$-CGRP receptors, comprises 3 parts: receptor activity modifying protein 1 , calcitoninlike receptor, and lastly receptor component protein.

The clinical use in rats demonstrated that capsaicin does not release substrate $\mathrm{P}$ from the trigeminal preparations which is responsible for neurogenic inflammation especially in humans. Instead, CGRP itself dilates the arterioles and then sensitizes neighboring sensory terminal nerve fibers. It is now clinically used in cluster headache or migraine which is exceptionally beneficial [57].

\section{Skin Health and Capsaicin}

A large number of studies pinpoint to the fact that stress-oriented changes could initiate or even aggravate various dermatological conditions. These changes include from skin cancer to inflammatory skin diseases such as acne, atopic dermatitis (AD), seborrheic eczema, psoriasis, prurigo nodularis, lichen planus, chronic urticaria, rosacea, and alopecia areata. In the skin, TRPV1 receptors are abundantly present in either neural or nonneural structures [54]. Whenever TRPV1 is activated, it helps to induce a second message through calcium $\left(\mathrm{Ca}^{2+}\right)$ influx in the epidermal keratinocytes. This entry of $\mathrm{Ca}^{2+}$ reduces inflammatory response one side, thereby decreasing harmful cutaneous stimulation. Capsaicin binding and induction, for the first time, desensitizes to the nervous system for burning sensation. The seminal studies illustrate fully that nociceptor activation releases proinflammatory neuropeptides [57].

Few studies have evaluated the clinical pharmacokinetics of orally administered capsaicin [58]. After an acute ingestion of $5 \mathrm{~g}$ of a capsaicin-rich hot pepper extract, a peak serum capsaicin level of 8.2 NM was observed after $45 \mathrm{~min}$. After an hour later, capsaicin was no longer detectible, presumably owing to rapid hepatic metabolism [59]. In mice given a bolus dose of $10 \mathrm{mg} / \mathrm{kg}$ of capsaicin, far higher than that could be expected to be used in humans, the peak serum concentration was about $3 \mu \mathrm{M}$; after $8 \mathrm{~h}$, capsaicin was undetectable in the serum. It is therefore reasonable to expect that clinically tolerable intakes of capsaicin will achieve serum concentrations in the nanomolar range. Although capsaicin can inhibit certain voltage-sensitive calcium channels with an $\mathrm{EC}_{50}$ of 5 $\mu \mathrm{M}$ or higher $[60,61]$, it does not appear likely that this effect would be germane with feasible oral intakes of capsaicin in humans [61].

\section{Dietary Capsaicin and Skin Dysfunction}

The capsaicin-induced anti-inflammatory responses are proposed through the activation of the TRPV1 receptor. This activation causes the nerve endings to release proinflammatory neuropeptides, such as SP and CGRP [62]. The release of these important neuropeptides is activated by CGRP receptors and neurokinin 1 . As a result, they lessen the dilation of vessels and increase vascular permeability. Neuropeptides which are released encourage degranulation of mast cells. Orientation of these cells increases the volume of capsaicin-induced neurogenic inflammation [63].

\section{Skin Permeation}

The use of capsaicin tropically is found to be effective in management of other skin disorders, shingles, muscle strain, arthritis-related disorders, diabetic neuropathy, and pain disorders [64]. In an additional old study, Desai et al.,[65] showed that capsaicin cream with 3 different concentrations $(0.025,0.5$, and $1.0 \%)$ acts well on aquagenic pruritus patients. This is linked to the TRPV1 re- 
ceptor and histamine-related itching [64]. Today, capsaicin oil-in-water nanoemulsions show complete successful results that enhanced skin permeation.

In a phase IV trial, comparison and efficacy of capsaicin in standard peripheral neuropathy treatment showed that $8 \%$ patch provided noninferior pain relief to pregabalin. Use of higher concentrations seems to produce transient adversative effects that include application site reaction, pain, pruritus, skin erythema, papules, and a transient increase in arterial blood pressure immediately after the application [64].

\section{Skin Inflammation}

In modern lifestyle, daily ups and downs create stress, which not only affects body systems but also their running physiology. Various studies in the last decade exhibit able evidence which shows that stress activity involves cutaneous neurogenic reaction $[65,66]$. Inflammation of neurological tissues that are potentially involved in skin could progress as inflammatory dermatological diseases [67]. A small number of nano-based ethosomes, transfersomes, and cubosomes are available that could deliver capsaicin to the skin site. Nanoemulsions tend to produce advantageous results as they have small droplet size and high capsaicin load capacity and are easy to manufacture. These qualities produce higher permeability without skin vexation and relief to patients [68]. Ghiasi and colleagues [63] in a recent publication showed that, in rats, use of nanoemulsion/cream/gel, with a median droplet size of 13-14 $\mathrm{nm}$, having prolonged 8-month stability, reduces skin inflammation edema within $2-3 \mathrm{~h}$ after application [68].

In a study of an antinociception therapeutic potential, it was shown that nociceptive nerve fibers tend to show sensitivity to capsaicin. Thereby, modulate activity of neurons increases SP releases from unmyelinated nerve endings of the skin, and later degranulation of cutaneous mast cells occurs [69]. A study on rats by Kim et al, [70] specified that use of siTNFa in assemblage with $2.5 \mathrm{mg}$ of capsaicin nanoparticle encapsulation for 5 days yielded complete treatment of inflamed versus normal looking skin.

Permeability and anti-inflammatory effects of lornoxicon in nanoemulsions (100-200 nm) are greatly increased. Use of aspirin- or capsaicin-derived nanoemulsion reveals excellent skin penetration and permeation which is proven by laser scanning microscopy analysis [70].

\section{Atopic Dermatitis}

$\mathrm{AD}$ is a skin-related inflammatory disease which is mostly seen among children. $\mathrm{AD}$ is a multiplex disease that has a genetic predisposition combined with an immune response as well as environmental factors [71]. Previous studies documented that various animal models have been developed for the investigation of $\mathrm{AD}$ [72]. A study was conducted by Back et al. [68] on a rat model; in this model, symptom development after weaning is followed by increases in the levels of serum IgE and skin NGF, IL-4, and IL-13 at approximately 3 weeks after injection [73]. In addition, this model also sides asthma-like airway inflammation [74]. Murakami et al. [71] indicated that symptoms of $\mathrm{AD}$ such as dermatitis and scratching behavior are persuaded by the neonatal injection of capsaicin [75]. Capsaicin triggers the cation channel TRPV1 and also revealed its antioxidant as well as anticancer effects. Moreover, in the recent treatment with the capsaicin analog, allergic reactions and $\mathrm{AD}$ symptoms were significantly reduced in NC/Nga mice [76]. Hiura [73] revealed that high doses of capsaicin seem to deploy different effects on the epidermis and neuronal system [77]. In addition, capsaicin frequently induces the death of TRPV-expressing dorsal root ganglion neurons. Apart from the existence of a 3-week lag period before the symptom development after capsaicin injection, the observations that cutaneous nerve fibers are lost, hair growth delayed, and skin NGF expression increased [73] suggest that changes in the internal milieu such as dysregulation of TRPV1-expressing cells, followed by compensatory events, may trigger symptom development.

Atopic skin is a condition that happens due to the disturbed epidermal differentiation and increased proliferation, triggering skin barrier dysfunction [71]. Moreover, at the molecular level, changes in many proteins have been investigated as possibly causative of AD development [78]. Among such changes, loss-of-function genetic mutations in the filaggrin gene strongly predispose to $A D$. In capsaicin-treated rats, filaggrin immunoreactivity was evident in both nonlesional skin and lesional skin. Filaggrin is defined as a large precursor protein that is subsequently proteolyzed into monomeric filaggrin in the stratum corneum [79]. Aberrant proteolytic processing of profilaggrin has been correlated with skin barrier dysfunction and $\mathrm{AD}$ development [80]. For the proper functioning of other skin barrier-related proteins such as corneodesmosin (CDSN), appropriate functioning of proteases is very important [81]. Furthermore, various proteases are also involved in CDSN and profilaggrin ac- 
Fig. 3. Mechanism of capsaicin-evoked pain sensation. BoNTA, onabotulinum neurotoxin A; CGRP-R, calcitonin-generelated peptide receptor complex; GEPANTs, CGRP receptor antagonists; mABs, monoclonal antibodies; TRPV1, transient receptor potential cation channel, subfamily $\mathrm{V}$, member 1 .

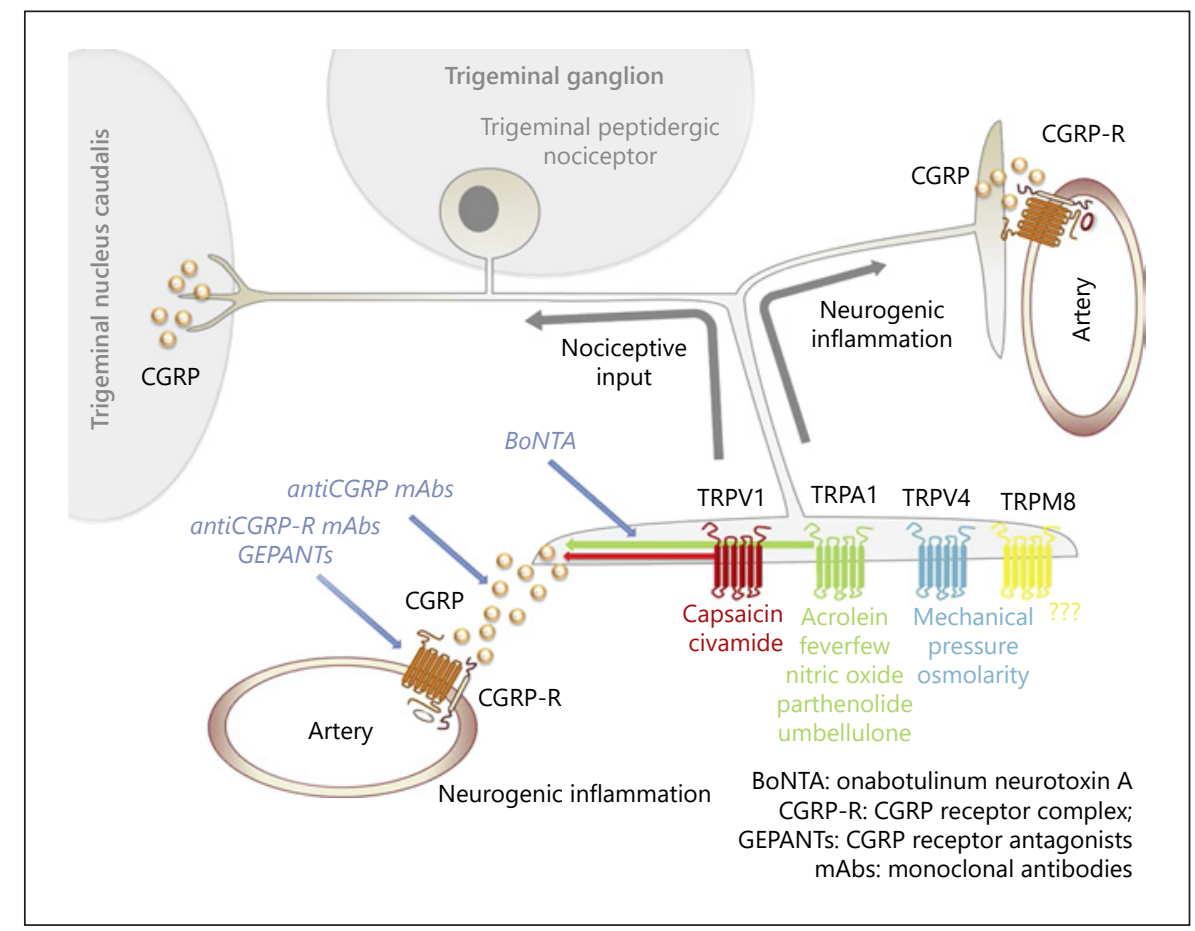

tivities. CDSN and profilaggrin directly cleave by the kallikrein (KLK)-related peptidases 5 and 7 [82, 83]. In addition, matriptase-, prostasin-, or Alox12b-knockout mice exhibit reduced profilaggrin cleavage in the epidermis [84-86], which is normally a rich source of proteases. Numerous proteases and protease inhibitors are expressed as epidermal keratinocytes differentiate [87]. These proteases are vital because of epidermal homeostasis; dysregulation of proteolytic pathways is now recognized as the mechanism underlying a growing number of skin diseases [87]. For instance, deficient matriptase activity causes severe skin barrier dysfunction and postnatal death [88]. Matriptase may be used to regulate intracellular ion homeostasis by controlling the epithelial sodium channel and the voltage-gated calcium channel, in turn regulating epidermal differentiation.

\section{Psoriasis}

Psoriasis is the most prevalent, chronic, inflammatory, and multisystem disease with primarily skin and joint manifestations that affects millions of people worldwide with a deleterious impact on their quality of life [89-93]. The term psoriasis, derived from the Greek word "psora," can also be translated as "to itch" [94]. Itch in psoriasis has often been underappreciated and accordingly often overlooked as a symptom requiring consideration in disease management $[95,96]$.

Among the most prevalent symptoms of psoriasis such as scaling, thickening of skin lesion, and redness, itch is not visible [90]. Historically, itch has been used to differentiate $\mathrm{AD}$ from psoriasis - the former being characterized pruritic, while the latter has often been considered nonpruritic. In addition, a recent meta-analysis of data from 22 clinical trials showed no significant difference in baseline itch between psoriasis and AD [97]. Previous studies demonstrated that itch is the most prevalent criterion for $\mathrm{AD}$ as well as a most important vital end point in $\mathrm{AD}$ studies $[98,99]$. In addition, itch is recognized as the most oppressive symptom of psoriasis. Moreover, all psoriasis individuals are affected by itch [100-102]. Furthermore, itch with unfettered effect has an adverse impact on social, physical, and psychological well-being [95]. Besides this, there are several therapeutic options available for the treatment of psoriasis such as lesions on skin, but limited options are available for the management of itch symptoms because of incomplete understanding of psoriasis-associated itch [103-105]. Although itch is a very distressful symptom, guidance and management specifically for itch is not readily available (Fig. 3). 
Fig. 4. Potential pathophysiology of itch in psoriasis. NGF, nerve growth factor; TRPV1, transient receptor potential cation channel, subfamily V, member 1 ; SP, substance $\mathrm{P}$.

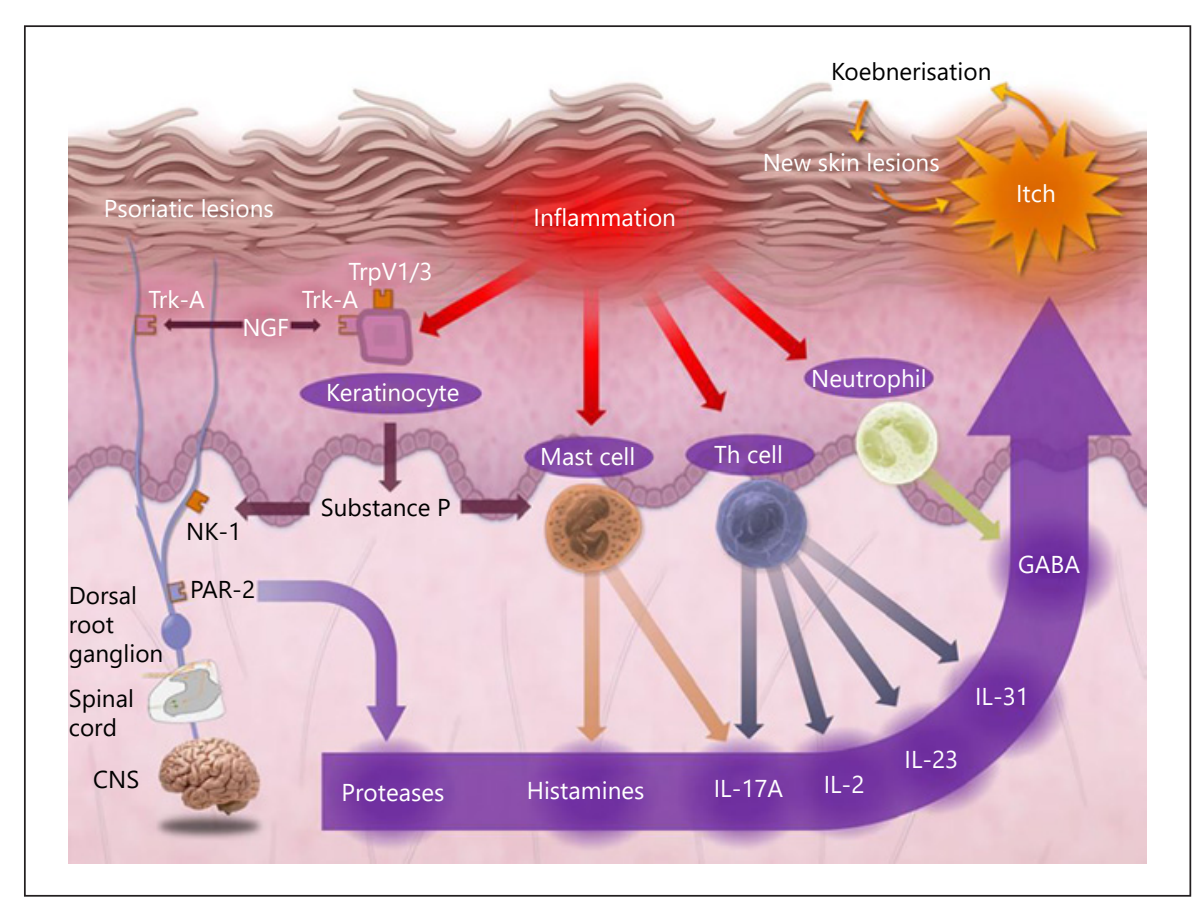

\section{Pathophysiology of Itch in Psoriasis}

The exact pathophysiology of psoriasis pruritus is not known. Various factors may contribute in the development of psoriasis (Fig. 4). The severity of psoriasis interrelated with itch is still not completely clear, as patients have complained itch on both lesions as well as healthy skin [102]. Extreme itching and scratching of the skin may cause the development of new psoriatic skin lesions in response to that trauma. According to the Koebner phenomenon that is defined as the development of psoriasis at sites of traumatized skin [106], this may constitute a key component in the vicious itch-scratch cycle that can further exacerbate the symptom if itch remains uncontrolled and unmanaged [106].

Numerous substances have been associated with itchy skin in psoriasis, such as nerve growth factor (NGF), SP, CGRP, neuropeptide $\mathrm{Y}$, and protein gene product 9.5 (PGP 9.5). In itch skin, factors such NGF and the number of NGF-immunoreactive keratinocytes and PGP 9.5-immunoreactive nerve fibers have been increased and also correlate with itch intensity [107]. NGF high-affinity receptor TrkA is highly expressed in the epidermis and dermal nerve fibers, and this also correlates with itch intensity [107]. In itchy psoriatic skin, keratinocytes and nerve fibers contain elevated level of expression of SP and its receptor [108]. Moreover, the inhibition of SP by capsaicin has been shown to significantly reduce itch in pa- tients with psoriasis, supporting a potential role of this neuropeptide in the pathophysiology of psoriatic itch [108].

\section{Pain Amplification Syndrome}

Human nervous system is equipped with features of plasticity and modifiability. The malleability is modulated with the intrinsic excitability or synaptic communication, release of chemicals, altered local protein expression, or its posttranslational changes [107]. This results in neuron de novo output in structural alteration and forms or loss of the cell that gives them new connectivity. It is now established that neural plasticity is well illustrative in nociceptive circuits in CNS [106].

Various studies showed that the TRPV1 antagonist plays a potential role in prevention of pain from going acute to chronic state. This happened to be due to the provocation of heterotopic long-term potentiation by capsaicin. Furthermore, the usage of capsaicin patch reduced pain by $71 \%$ compared to the other control site [106]. In the nociceptor, local activation mediators and peripheral inflammation of the injured tissue response by immune cells decrease the transducer ion channel/receptor expression. This is the result of phosphorylation of proteins in nociceptor termini that make them effectively sensitized for lower capsaicin stimuli [108]. 


\section{Conclusion}

Capsaicin is derived from the family known as the vanilloid family. It binds with the TRPV1 receptor and performs its function. Capsaicin is stimulated by physical abrasion, heat, and also protons. It plays a vital role in the eradication of skin inflammation, psoriasis, and atopic dermatitis and overcoming chronic pain amplification syndrome. Inhibition of SP by capsaicin has been shown to significantly reduce itch in patients with psoriasis, supporting a potential role of this neuropeptide in the pathophysiology of psoriatic itch. Capsaicin dysregulates epidermal proteases such as matriptase and KLKs and alters profilaggrin and CDSN proteolysis, possibly explaining the observed skin manifestations. Such events may be influenced by the extent of postnatal epidermal development. Furthermore, the usage of capsaicin patch reduced pain by $71 \%$ compared to the other control site.

\section{Conflict of Interest Statement}

The authors declare no conflicts of interest.

\section{Funding Sources}

The authors did not receive any funding.

\section{Author Contributions}

I express my deepest gratitude to my coauthors, Dr. Syed Amir Gillani, Dr. Ayesha Basharat, Dr. Mian Anjum Muratza, and Ms. Benazir Basharat, who helped me in the selection of the topic and analyzation of the data. I am also thankful to Ms. Faiza Iftikhar who helped me in the intellectual input and design of the study.

\section{References}

1 Aresti JS, El SA. Microbiota and gut neuropeptides: a dual action of antimicrobial activity and neuroimmune response. ISO. 2019; 236(5):1597.

2 de Aguiar AC, Sales LP, Coutinho JP, Barbero GF, Godoy HT, Martínez J. Supercritical carbon dioxide extraction of Capsicum peppers: global yield and capsaicinoid content. J Supercrit Fluids. 2013;81:210-6.

3 Rhim J-W, Hong S-I. Effect of water activity and temperature on the color change of red pepper (Capsicum annuum L.) powder. Food Sci Biotechnol. 2011;20(1):215-22.

4 O’Neill J, Brock C, Olesen AE, Andresen T, Nilsson M, Dickenson AH. Unravelling the mystery of capsaicin: a tool to understand and treat pain. Pharmacol Rev. 2012;64(4):93971.

5 Chapa-Oliver A, Mejía-Teniente L. Capsaicin: from plants to a cancer-suppressing agent. Molecules. 2016;21(8):931.

6 Du G-H. Natural small molecule drugs from plants. Springer; 2018.

7 Antonio A, Wiedemann LSM, Veiga VF. The genus Capsicum: a phytochemical review of bioactive secondary metabolites. RSC Adv. 2018;8(45):25767-84.

8 Nelson EK. The constitution of capsaicin, the pungent principle of Capsicum. J Am Chem Soc. 1919;41(7):1115-21.

9 Suresh D, Srinivasan K. Tissue distribution \& elimination of capsaicin, piperine \& curcumin following oral intake in rats. Indian J Med Res. 2010;131(5):682.
10 Baenas N, Belović M, Ilic N, Moreno DA, García-Viguera C. Industrial use of pepper (Capsicum annum L.) derived products: technological benefits and biological advantages. Food Chem. 2019;274:872-85.

11 Antonio A, Wiedemann LSM, Veiga VF. The genus Capsicum: a phytochemical review of bioactive secondary metabolites. RSC Adv. 2018;8(45):25767-84.

12 Sganzerla M, Coutinho JP, de Melo AMT, Godoy HT. Fast method for capsaicinoids analysis from Capsicum chinense fruits. Food Res Int. 2014;64:718-25.

13 Sun F, Xiong S, Zhu Z. Dietary capsaicin protects cardiometabolic organs from dysfunction. Nutrients. 2016;8(5):174.

14 Basith S, Cui M, Hong S, Choi S. Harnessing the therapeutic potential of capsaicin and its analogues in pain and other diseases. Molecules. 2016;21(8):966.

15 Myszka K, Leja K, Majcher M. A current opinion on the antimicrobial importance of popular pepper essential oil and its application in food industry. J Essent Oil Res. 2019; 31(1):1-18.

16 Yang F, Zheng J. Understand spiciness: mechanism of TRPV1 channel activation by capsaicin. Protein Cell. 2017;8(3):169-77.

17 Fernando RRS, Swaminathan V. Effect of a nutrition education program on nutritional knowledge and dietary behaviour of children in the age group of 7 to 9 years. Int J Appl Res. 2015;1(12):445-9.

18 Fattori V, Hohmann MS, Rossaneis AC, Pinho-Ribeiro FA, Verri WA. Capsaicin: current understanding of its mechanisms and therapy of pain and other pre-clinical and clinical uses. Molecules. 2016;21(7):844.
19 Randhawa PK, Jaggi AS. Investigating the involvement of TRPV 1 ion channels in remote hind limb preconditioning-induced cardioprotection in rats. Naunyn Schmiedebergs Arch Pharmacol. 2017;390(2):117-26.

20 Gharat L, Szallasi A. Medicinal chemistry of the vanilloid (capsaicin) TRPV1 receptor: current knowledge and future perspectives. Drug Dev Res. 2007;68(8):477-97.

21 McCarty MF, DiNicolantonio JJ, O'Keefe JH. Capsaicin may have important potential for promoting vascular and metabolic health. Open Heart. 2015;2(1):e000262.

22 McCarty MF, DiNicolantonio JJ, O'Keefe JH. Capsaicin may have important potential for promoting vascular and metabolic health. Open Heart. 2015;2(1):e000262.

23 Fattori V, Hohmann MS, Rossaneis AC, Pinho-Ribeiro FA, Verri WA. Capsaicin: current understanding of its mechanisms and therapy of pain and other pre-clinical and clinical uses. Molecules. 2016;21(7):844.

24 Vangeel L, Voets T. Transient receptor potential channels and calcium signaling. Cold Spring Harb Perspect Biol. 2019;11(6): a035048.

25 Mulier M, Vriens J, Voets T. TRP channel pores and local calcium signals. Cell Calcium. 2017;66:19-24.

26 Fattori V, Hohmann MS, Rossaneis AC, Pinho-Ribeiro FA, Verri WA. Capsaicin: current understanding of its mechanisms and therapy of pain and other pre-clinical and clinical uses. Molecules. 2016;21(7):844.

27 Vangeel L, Voets T. Transient receptor potential channels and calcium signaling. Cold Spring Harb Perspect Biol. 2019;11(6): a035048. 
28 Wood BM. A study of the spatiotemporal regulation of calmodulin kinase superfamily members in cardiac myocytes. Davis: University of California; 2017.

29 Vangeel L, Voets T. Transient receptor potential channels and calcium signaling. Cold Spring Harb Perspect Biol. 2019;11(6): a035048.

30 Yoshie K, Rajendran PS, Massoud L, Kwon O, Tadimeti V, Salavatian S, et al. Cardiac vanilloid receptor-1 afferent depletion enhances stellate ganglion neuronal activity and efferent sympathetic response to cardiac stress. Am J Physiol Heart Circ Physiol. 2018;314(5): H954-66.

31 Christie S, Wittert GA, Li H, Page AJ. Involvement of TRPV1 channels in energy homeostasis. Front Endocrinol. 2018;9:420.

32 Zhang W-C, Zheng XJ, Du LJ, Sun JY, Shen ZX, Shi C, et al. High salt primes a specific activation state of macrophages, $\mathrm{M}(\mathrm{Na})$. Cell Res. 2015;25(8):893-110.

33 Cao YQ, Mantyh PW, Carlson EJ, Gillespie AM, Epstein CJ, Basbaum AI. Primary afferent tachykinins are required to experience moderate to intense pain. Nature. 1998 392(6674):390-4.

34 McCoy ES, Taylor-Blake B, Street SE, Pribisko AL, Zheng J, Zylka MJ. Peptidergic CGRPa primary sensory neurons encode heat and itch and tonically suppress sensitivity to cold. Neuron. 2013;78(1):138-51.

35 Salmon AM, Damaj I, Sekine S, Picciotto MR, Marubio L, Changeux JP. Modulation of morphine analgesia in alphaCGRP mutant mice. Neuroreport. 1999;10(4):849-54.

36 Zhang L, Hoff AO, Wimalawansa SJ, Cote GJ, Gagel RF, Westlund KN. Arthritic calcitonin/ alpha calcitonin gene-related peptide knockout mice have reduced nociceptive hypersensitivity. Pain. 2001;89(2-3):265-73.

37 Gustavsson N, Wu B, Han W. Calcium sensing in exocytosis. Adv Exp Med Biol. 2012; 740:731-57.

38 Zhao B, Wang HB, Lu YJ, Hu JW, Bao L, Zhang X. Transport of receptors, receptor signaling complexes and ion channels via neuropeptide-secretory vesicles. Cell Res. 2011; 21(5):741-53.

39 Malin SA, Davis BM, Koerber HR, Reynolds IJ, Albers KM, Molliver DC. Thermal nociception and TRPV1 function are attenuated in mice lacking the nucleotide receptor $\mathrm{P} 2 \mathrm{Y} 2$. Pain. 2008;138(3):484-96.

40 Moriyama T, Iida T, Kobayashi K, Higashi T, Fukuoka T, Tsumura $\mathrm{H}$, et al. Possible involvement of P2Y2 metabotropic receptors in ATP-induced transient receptor potential vanilloid receptor 1-mediated thermal hypersensitivity. J Neurosci. 2003;23(14):6058-62.

41 Tominaga M, Wada M, Masu M. Potentiation of capsaicin receptor activity by metabotropic ATP receptors as a possible mechanism for ATP-evoked pain and hyperalgesia. Proc Natl Acad Sci U S A. 2001;98(12):6951-6.

42 Zheng W, Wen $\mathrm{H}$. Heat activation mechanism of TRPV1: new insights from molecular dynamics simulation. Temperature. 2019; 6(2):120-31.

43 Winkler M, Moraux T, Khairy HA, Scott RH, Slawin AM, O'Hagan D. Synthesis and vanilloid receptor (TRPV1) activity of the enantiomers of a-fluorinated capsaicin. ChemBioChem. 2009;10(5):823-8.

44 Vandewauw I, De Clercq K, Mulier M, Held K, Pinto S, Van Ranst N, et al. A TRP channel trio mediates acute noxious heat sensing. Nature. 2018;555(7698):662.

45 Gharat L, Szallasi A. Medicinal chemistry of the vanilloid (capsaicin) TRPV1 receptor: current knowledge and future perspectives. Drug Dev Res. 2007;68(8):477-97.

46 Christie S, Wittert GA, Li H, Page AJ. Involvement of TRPV1 channels in energy homeostasis. Front Endocrinol. 2018;9:420

47 Cho SC, Lee H, Choi BY. An updated review on molecular mechanisms underlying the anticancer effects of capsaicin. Food Sci Biotechnol. 2017;26(1):1-13.

48 McArthur JR, et al. Analgesic transient receptor potential vanilloid-1-active compounds inhibit native and recombinant T-type calcium channels. Br J Pharmacol. 2019.

49 Fattori V, Hohmann MS, Rossaneis AC, Pinho-Ribeiro FA, Verri WA. Capsaicin: current understanding of its mechanisms and therapy of pain and other pre-clinical and clinical uses. Molecules. 2016;21(7):844.

50 Rezaeian AH, Isokane T, Nishibori M, Chiba M, Hiraiwa N, Yoshizawa M, et al. aCGRP and $\beta$ CGRP transcript amount in mouse tissues of various developmental stages and their tissue expression sites. Brain Dev. 2009;31(9): 682-93.

51 Khalil M, Alliger K, Weidinger C, Yerinde C Wirtz S, Becker C, et al. Functional role of transient receptor potential channels in immune cells and epithelia. Front Immunol. 2018;9:174.

52 Janssens PL, Hursel R, Martens EA, Westerterp-Plantenga MS. Acute effects of capsaicin on energy expenditure and fat oxidation in negative energy balance. PLoS One. 2013; 8(7):e67786.

53 Jolayemi ATE. Capsaicin: aromatic basis and mechanism of action: an example of positive inhibition. Aromat Med Plants. 2017:239.

54 Kang JH, Tsuyoshi G, Le Ngoc H, Kim HM, $\mathrm{Tu} \mathrm{TH}$, Noh HJ, et al. Dietary capsaicin attenuates metabolic dysregulation in genetically obese diabetic mice. J Med Food. 2011; 14(3):310-5.

55 McCarty MF, DiNicolantonio JJ, O'Keefe JH. Capsaicin may have important potential for promoting vascular and metabolic health. Open Heart. 2015;2(1):e000262.

56 Georgescu S-R, Sârbu M-I, Matei C, Ilie M, Caruntu C, Constantin C, et al. Capsaicin: friend or foe in skin cancer and other related malignancies? Nutrients. 2017;9(12):1365.

57 McCarty MF, DiNicolantonio JJ, O'Keefe JH. Capsaicin may have important potential for promoting vascular and metabolic health. Open Heart. 2015;2(1):e000262.
58 Basith S, Cui M, Hong S, Choi S. Harnessing the therapeutic potential of capsaicin and its analogues in pain and other diseases. Molecules. 2016;21(8):966.

59 Lotti T, Hautmann G, Panconesi E. Neuropeptides in skin. J Am Acad Dermatol. 1995; 33(3):482-96.

60 Li H, Yu B, Li J, Su L, Yan M, Zhu Z, et al. Overexpression of IncRNA H19 enhances carcinogenesis and metastasis of gastric cancer. Oncotarget. 2014;5(8):2318.

61 Grigore O, Mihailescu AI, Solomon I, Boda D, Caruntu C. Role of stress in modulation of skin neurogenic inflammation. Exp Ther Med. 2019;17(2):997-1003.

62 Căruntu C, Boda D, Musat S, Căruntu A, Mandache E. Stress-induced mast cell activation in glabrous and hairy skin. Mediat Inflamm. 2014;2014:105950.

63 Ghiasi Z, Esmaeli F, Aghajani M, GhaziKhansari M, Faramarzi MA, Amani A. Enhancing analgesic and anti-inflammatory effects of capsaicin when loaded into olive oil nanoemulsion: an in vivo study. Int J Pharm. 2019;559:341-7.

64 Yaksh TL, Di Nardo A. Complexity of systems and actions underlying neurogenic inflammation. Semin Immunol. 2018 May;40(3) 225-8.

65 Desai PR, Marepally S, Patel AR, Voshavar C, Chaudhuri A, Singh M. Topical delivery of anti-TNFa siRNA and capsaicin via novel lipid-polymer hybrid nanoparticles efficiently inhibits skin inflammation in vivo. J Control Release. 2013;170(1):51-63.

66 Gupta D. Atopic dermatitis. Med Clin North Am. 2015;99(6):1269.

67 Jin H, He R, Oyoshi M, Geha RS. Animal models of atopic dermatitis. J Invest Dermatol. 2009;129(1):31

68 Back SK, Jeong K-Y, Li C, Lee J, Lee S-B, Na HS. Chronically relapsing pruritic dermatitis in the rats treated as neonate with capsaicin; a potential rat model of human atopic dermatitis. J Dermatol Sci. 2012;67(2):111.

69 Sclafani A., Ackroff K.. Capsaicin-induced visceral deafferentation does not attenuate flavor conditioning by intragastric fat infusions in mice. Physiol Behav. 2019;208: 112586

70 Kim M, Kwon Y, Jung H S, Kim Y, Jeoung D. FceRI-HDAC3-MCP1 Signaling Axis Promotes Passive Anaphylaxis Mediated by Cellular Interactions. Int J Mol Sci. 2019;20(19): 4964.

71 Murakami K, Ito M, Htay HH, Tsubouchi R, Yoshino M. Antioxidant effect of capsaicinoids on the metal-catalyzed lipid peroxidation. Biomed Res. 2001;22(1):15.

72 Oh M S, Hong J Y, Kim M N, Kwak E J, Kim S Y, Kim E G, et al. Activated Leukocyte Cell Adhesion Molecule Modulates Th2 Immune Response in Atopic Dermatitis.. Allergy Asthma Immunol Res. 2019;11(5):677-690.

73 Hiura A. Neuroanatomical effects of capsaicin on the primary afferent neurons. Arch Histol Cytol. 2000;63(3):199-215. 
74 Margolis DJ, Mitra N, Wubbenhorst B, Nathanson KL. Filaggrin sequencing and bioinformatics tools. Arch Dermatol Res. 2020; 312(2):155-8.

75 Trzeciak M, Sakowicz-Burkiewicz M, Wesserling M, Gleń J, Dobaczewska D, Bandurski $\mathrm{T}$, et al. Altered expression of genes encoding cornulin and repetin in atopic dermatitis.. Int Arch Allergy Immunol. 2017;172(1):11-19.

76 Sandilands A, Sutherland C, Irvine $A D$, McLean WHI. Filaggrin in the frontline: role in skin barrier function and disease. J Cell Sci. 2009;122(9): 1285.

77 Ishida-Yamamoto A, Igawa S. The biology and regulation of corneodesmosomes. Cell Tissue Res. 2014;360(3):477.

78 Caubet C, Jonca N, Brattsand M, Guerrin M, Bernard D, Schmidt R, et al. Degradation of corneodesmosome proteins by two serine proteases of the kallikrein family, SCTE/ KLK5/hK5 and SCCE/KLK7/hK7. J Invest Dermatol. 2004;122(5):1235.

79 Sakabe J-i., Yamamoto M, Hirakawa S, Motoyama A, Ohta I, Tatsuno K, et al. Kallikreinrelated peptidase 5 functions in proteolytic processing of profilaggrin in cultured human keratinocytes. J Biol Chem. 2013;288(24): 17179 .

80 Epp N, Fürstenberger G, Müller K, de Juanes S, Leitges M, Hausser I, et al. 12R-lipoxygenase deficiency disrupts epidermal barrier function. J Cell Biol. 2007;177(1):173.

81 Leyvraz C, Charles R-P, Rubera I, Guitard M, Rotman S, Breiden B, et al. The epidermal barrier function is dependent on the serine protease CAP1/Prss8. J Cell Biol. 2005;170(3): 487.

82 List K, Szabo R, Wertz PW, Segre J, Haudenschild CC, Kim S-Y, et al. Loss of proteolytically processed filaggrin caused by epidermal deletion of matriptase/MT-SP1. J Cell Biol. 2003;163(4):901.

83 de Veer SJ, Furio L, Harris JM, Hovnanian A. Proteases: common culprits in human skin disorders. Trends Mol Med. 2014;20(3):166.

84 Ovaere P, Lippens S, Vandenabeele P, Decler$\mathrm{cq} \mathrm{W}$. The emerging roles of serine protease cascades in the epidermis. Trends Biochem Sci. 2009;34(9):453.

85 WHO. Global report on psoriasis. Geneva, Switzerland: WHO Press; 2016.
86 Menter A, Gottlieb A, Feldman SR, Van Voorhees AS, Leonardi CL, Gordon KB, et al. Guidelines of care for the management of psoriasis and psoriatic arthritis: section 1 . Overview of psoriasis and guidelines of care for the treatment of psoriasis with biologics. J Am Acad Dermatol. 2008;58(5):826-50.

87 Moller AH, Erntoft S, Vinding GR, Jemec GB. A systematic literature review to compare quality of life in psoriasis with other chronic diseases using EQ-5D-derived utility values. Patient Relat Outcome Meas. 2015;6:167-77.

88 Rachakonda TD, Schupp CW, Armstrong AW. Psoriasis prevalence among adults in the United States. J Am Acad Dermatol. 2014; 70(3):512-6.

89 American Academy of Dermatology Work Group; Menter A, Menter A, Korman NJ, Elmets CA, Feldman SR, Gelfand JM, et al. Guidelines of care for the management of psoriasis and psoriatic arthritis: section 6 . Guidelines of care for the treatment of psoriasis and psoriatic arthritis: case-based presentations and evidence-based conclusions. J Am Acad Dermatol. 2011;65(1):137-74.

90 Komiya E, Tominaga M, Kamata Y, Suga Y, Takamori K. Molecular and Cellular Mechanisms of Itch in Psoriasis. Int J Mol Sci. 2020; 21(21):8406.

91 Szepietowski JC, Reich A. Itch in psoriasis management. Curr Probl Dermatol. 2016;50: 102-10.

92 Lebwohl MG, Kavanaugh A, Armstrong AW, Van Voorhees AS. US perspectives in the management of psoriasis and psoriatic arthritis: patient and physician results from the population-based Multinational Assessment of Psoriasis and Psoriatic Arthritis (MAPP) survey. Am J Clin Dermatol. 2016;17:87-97.

93 Shahwan KT, Kimball AB. Itch intensity in moderate-to-severe plaque psoriasis versus atopic dermatitis: a meta-analysis. J Am Acad Dermatol. 2017;76(6):1198-e1.

94 Lebwohl MG, Bachelez H, Barker J, Girolomoni G, Kavanaugh A, Langley RG, et al. Patient perspectives in the management of psoriasis: results from the population-based Multinational Assessment of Psoriasis and Psoriatic Arthritis survey. J Am Acad Dermatol. 2014;70(5):871-81.e1-30.

95 Szepietowski JC, Reich A. Pruritus in psoriasis: an update. Eur J Pain. 2016;20(1):41-6.

96 Amatya B, Wennersten G, Nordlind K. Patients' perspective of pruritus in chronic plaque psoriasis: a questionnaire-based study. J Eur Acad Dermatol Venereol. 2008;22:822-
97 Yosipovitch G, Goon A, Wee J, Chan YH, Goh CL. The prevalence and clinical characteristics of pruritus among patients with extensive psoriasis. $\mathrm{Br}$ J Dermatol. 2000; 143(5):969-73.

98 Szepietowski JC, Reich A, Wiśnicka B. Itching in patients suffering from psoriasis. Acta Dermatovenerol Croat. 2002;10(4):221-6.

99 Armstrong AW, Siegel MP, Bagel J, Boh EE, Buell M, Cooper KD, et al. From the medical board of the national psoriasis foundation: treatment targets for plaque psoriasis. J Am Acad Dermatol. 2017;76(2):290-8.

100 Bagel J, Gold LS. Combining topical psoriasis treatment to enhance systemic and phototherapy: a review of the literature. J Drugs Dermatol. 2017;16(12):1209-22.

101 Stull C, Grossman S, Yosipovitch G. Current and emerging therapies for itch management in psoriasis. Am J Clin Dermatol. 2016 17(6):617-24.

102 Chang SE, Han SS, Jung HJ, Choi JH. Neuropeptides and their receptors in psoriatic skin in relation to pruritus. Br J Dermatol. 2007;156(6):1272-7.

103 Kalayciyan A, Aydemir EH, Kotogyan A. Experimental Koebner phenomenon in patients with psoriasis. Dermatology. 2007; 215(2):114-7.

104 Nakamura M, Toyoda M, Morohashi M. Pruritogenic mediators in psoriasis vulgaris: comparative evaluation of itch-associated cutaneous factors. Br J Dermatol. 2003; 149(4):718-30.

105 Ellis CN, Berberian B, Sulica VI, Dodd WA, Jarratt MT, Katz HI, et al. A double-blind evaluation of topical capsaicin in pruritic psoriasis. J Am Acad Dermatol. 1993;29(3): $438-42$.

106 Khoutorsky A, Price TJ. Translational control mechanisms in persistent pain. Trends Neurosci. 2018;41(2):100-14.

107 Woolf CJ. Pain amplification-a perspective on the how, why, when, and where of central sensitization. J Appl Behav Res. 2018;23(2): e12124.

108 Henrich F, Magerl W, Klein T, Greffrath W, Treede RD. Capsaicin-sensitive C- and Afibre nociceptors control long-term potentiation-like pain amplification in humans. Brain. 2015;138(Pt 9):2505-20. 